\title{
Comparison Between Gross Motor Skills Performance and 7-Years-Old Children with Controlled Effect of Residential Area
}

\author{
A Nadzmi ${ }^{*}$, M R Abdullah ${ }^{2}$, A B H M Maliki ${ }^{3}$, Faiza Renaldi ${ }^{4}$ and Sukono ${ }^{5}$ \\ ${ }^{1}$ Faculty of Applied Science Social University of Sultan Zainal Abidin, 21300 University of Sultan Zainal Abidin, \\ Kampus Gong Badak, Terengganu, Malaysia. \\ ${ }^{2,3}$ East Coast Environment Research Institute, 21300 University of Sultan Zainal Abidin, Kampus Gong Badak, \\ Terengganu, Malaysia \\ ${ }^{4}$ Informatics Department, Universitas Jenderal Achmad Yani, Bandung Barat, Indonesia \\ ${ }^{5}$ Department of Mathematics, Faculty of Mathematics and Natural Sciences, Universitas Padjadjaran, Bandung, \\ Indonesia \\ *Corresponding author.Email: razali896@ymail.com
}

\begin{abstract}
The underweight is a health problem and currently growing especially in low- and middle-income country and this problem need to be concern aside from overweight and obesity. The underweight is currently increasing due to the modernization that cause sedentary lifestyle and this lifestyle affecting children so much. The aim of this study is to identify the major and minor factor of gross motor skills from the underweight 7 years old children with controlled effect of residential location. Another aim is to compare the capabilities of gross motor skills performances between children's gender with the controlled effect of residential location. Participants are 5027 seven years old children, 3394 males with weight $( \pm 2.0247)$, height $( \pm 6.3803)$ and age $( \pm 0.2866)$ and 1634 female with weight $( \pm 0.2837)$, height $( \pm 1.9322)$ and age $( \pm 6.4188)$ from national primary school in 14 states in Malaysia. Weight status included are only underweight based on WHO standard. Parameter for gross motor skills are power (Standing Broad Jump), flexibility (Sit and Reach), speed (20 metre sprint) and coordination (Hand Wall Toss). PCA and MANCOVA were used to analyse the data. Result showing there are two major factors for gross motor skills for underweight 7 years old children and there is significant differences between genders in term of gross motor skills performances. The comparison shows male significantly $(\mathrm{p}<0.05)$ dominating female in term of power, speed and coordination while female significantly $(\mathrm{p}<0.05)$ dominating male in term of flexibility.
\end{abstract}

Keywords: Gross Motor Skills Performances, 7 years-old Children, Residential Area

\section{INTRODUCTION}

Child development refers to the sequence of physical, behavioral, thinking and emotional changes that occur in a child from birth to early adulthood. In this process, the child transitions from reliance on parents / guardians to growing confidence. There are 5 areas of development in children development that is; cognitive development when the child learn on how to learn and solve problems, social and development control when child learning the ability to interact with others, including helping themselves and selfcontrol, speech and language development when the child start to both understand and use language, fine motor skills development when the child start to use the small muscle like hand or wrist, and lastly the gross motor skills development when children learn the ability of using the large muscles [1].

In these days, modernization have changed the human lifestyle dynamically, becoming more sedentary life style as in the past before the modernization, most people have to use many physical activities in their daily life [2]-[3]. This stating that the people at the past are more using their gross motor skills often. Gross motor skills are those that include whole body activity and include large muscles in the body to perform daily tasks, such as standing and walking, running and jumping, and sitting. Gross motor skills are important for children participating in age-related physical activities, and gross motor skills may play an 
important role for maintaining sufficient level of physical activity (PA) during life course [4] It also helps them get exercise and physical activity, which is important for a healthy lifestyle [5].

This modernization also affecting the children that in the past is more active person and today become more passive because of the sedentary lifestyle and because of this modernization too, it affecting the rural area also to become more undeveloped precisely on the community leisure life [2]. Sedentary lifestyle now is affecting the children physical performance from year to year. This is based on earlier repeated research on 29-year trends in body dimensional and physical fitness performance for children in China from 1985 to 2014, resulting in significant differences in the average body dimensional and physical fitness performance for each gender from 1985 to 2014 in both rural and urban areas [6].

Although this modernization has changed the lifestyle trend for children as the children becoming more obesity and overweight, the children in the world also suffering the underweight; which a underrated health-related problem that also give serious impact on health especially for children. WHO stating around $45 \%$ of deaths among children under 5 years of age are linked to undernutrition These mostly occur in low- and middle-income countries and at the same time, in these same countries, rates of childhood overweight and obesity are rising [7].

In Malaysia, The 2020 Global Nutrition Report [8], Malaysia, which objectively analyses the state of global nutrition, found that Malaysia is on track to reach the global goal for children under five years of age who are overweight, but is of course on track to meet the targets for stunted growth (low height-for-age) and malnutrition (low weight-for-height). According to the Global Nutrition Survey, Malaysia's malnutrition children prevalence is 11.5 percent in 2016 was higher than the 8.9 percent average for developing countries. The worldwide goal for childhood waste by 2025 is less than 5\%. The Global Nutrition Survey, as cited. Malaysia's low birth weight prevalence has marginally increased from 10 per cent in 2000 to 11.3 per cent in 2015, according to the study.

This is showing that the underweight are included of major factor of children death in the world which cannot be unseen. This problem is growing in Malaysia without the community aware of this problem because of the overrating problem of overweight and obesity. Aim of this research is to identify the major and minor factor for gross motor skills within the gender on 7 years old underweight children with the controlled effect of residential location and to compare the capabilities of gross motor skills performances between children's gender with the controlled effect of residential location.

\section{LITERATURE REVIEW}

\subsection{Children Development}

Children and youth whose developmental progress would be considered typical for each of the age groups [1]. For each age group be considered common. These activities are further categorised into five different fields or established areas: physical, physiological, social, mental and moral development area comprises short explanations of common behaviours in this area of development and suggested caregivers that can be used to improve growth. Furthermore, the age category of 6 to 8 years old they are making the transition from their childhood thinking to reasoned thinking based on a concrete fact based of their understanding [1]. This is similar in Piaget Cognitive Theory stating that in the 6-8 category, the children is starting to concrete their inner thought and become base of their thinking method [9].

\subsection{Gross motor skills performance}

Sufficient motor skills are important for children engaging in age-related physical activity, and gross motor skills can play a significant part in holding a sufficient amount of physical activity throughout their lifetime [4]. The aim of this research was to investigate the relationship between gross motor skills and PA in children as both metabolic and neuromuscular PA were studied. The result emphasises that the metabolism and neuromuscular systems of children are closely associated with gross motor skills and PA. In addition, PA's neuromuscular system with high tension interacts with gross motor.

The rising prevalence of obesity among children and young people is a major global public health problem [5]. This study examined the relationship between physical fitness and BMI between underweight and obese children and adolescents on the Chinese mainland. 22,681 children and teenagers from the Chinese continent aged 10-18 (1,300 boys and 11,381 girls). Substantial teenagers were more effective than their obese peers in lower limb strength, flexibility, agility and cardiorespiratory fitness, but worse in upper limb strength. The high chances of meeting a low physical fitness level have been significant for underweight children aged 10 to 11,12 to 13 and for girls aged 10 to 11 .

A study was executed to explore the differences in physical health, physical activity and sedentary behaviour between 7 to 11-year olds in Ardabil, Iran [10]. This study found that weight-bearing fitness, cardiorespiratory fitness and physical activity declined gradually as the BMI increased and sedentary activity increased. 


\subsection{Sedentary lifestyle}

A past study were conducted about examination of body dimensional patterns and physical activity test outcomes in 12-year-old Chinese children living in urban and rural areas for a 29-year period (1985-2014) [6]. Urban and rural children's height and weight dramatically increased from 1985 to 2014. In urban and rural children there was a general drop in physical health after 2000. Public health officials and parents must take immediate, concerted action to preserve or boost the physical fitness of children. A study is about to how the video games effecting the children and youth [3]. Active video games (AVGs) have become increasingly involved in growing physical activity in children and young people. Controlled studies indicate that AVG 's rise acutely light to low intensity physical activity, but results are less evident whether or how AVGs contributes to a rise in normal physical activity or decreases in sedentary behaviour. While AVGs can bring health benefits to special populations, there is not enough evidence to suggest AVGs to increase physical activity on a daily basis.

Another study was conducted to determine the difference in physical health among pre-school children with different BMIs, since even this age group has a growing problem with overweight and obesity. There were major body height variations between overweight and average kids and (ii) overweight and underweight kids. There were substantial variations in body weight and BMI for all races. With regard to agility tests, the largest differences for grip strength and wide jump standing were found. The sit and reach test showed no gaps between the classes. There was a negative association between general physical health and relative weight; general fitness in overweight children was lower than in obese or underweight children. As it is clear that, even for children in pre-school years, physical activity will at least partially mitigate the issue of excessive weight and boost children's overall health. This will decrease the prevalence of obesity-related diseases and a lack of practise in the future.

Another study were also conducted about to understand the awareness of prevalence and the causes in youth and young adults of moderate to intensive physical activity directs public health and policy strategies [11]. Female and young adults have not complied with prescribed physical activity recommendations and major differences have been identified by race and income levels. These data demonstrate opportunities for tailored programming and policy activities for physical activity.

\subsection{Muscle development}

A research conducted in order to study the effect of body mass on the development of a foot based on a foot type ranking [12]. Five foots forms have been identified: wide, strong, slim, short and long. There were substantial variations between foot styles in relation to the body mass index of children. Children with average weight had an almost equal distribution of all kinds of foot during the entire childhood. Flat, sturdy feet were more prevalent in children who were overweight, while underweight children displayed slimmer and longer feet. The effect of both excess and deficient mass could be confirmed based on a foot form classification for detailed foot morphology. Foot pain may then develop as a result of various musculoskeletal disorders. This, in turn, could discourage children from becoming active and therefore increase the risk of obesity.

\section{METHODOLOGY}

\subsection{Research Design}

This study is a quantitative study. Data collected is a primary data in a data classification of interval data and nominal data. This study is a comparative study and the sample measured by using field-based data collection.

\subsection{Validity}

Anthropometric validity refers to the measurement system that tests the degree to which the data is needed to determine the validity of the measurement instrument. In this study, most of the elements were measured for 4 variables are quantitative study and 2 variable are qualitative study [13]. Tools and instruments used in this study have high validity because of frequent use in scientific use in scientific research and nutrition movement.

\subsection{Consistency}

Reliability refers to the consistency of the measurement device to measure a variable or concept [14]. Reliability is influenced factors according to their systematic and unsystematic review that cause variation in measurement even using the same instrument. Unsystematic factor is more to the problem of the instrument with inconsistent measurements or instructions of the instrument that is not clear which affect the reliability of the instrument.

\subsection{Sample of study}

5028 participants were involved in this study from 1227 primary school located in all 14 states in Malaysia, including Sabah and Sarawak. Those participants were chosen from this research's focus that is targeting the 7 years-old underweight $(>18 \mathrm{~kg} / \mathrm{m} 2)$ primary school students [15]. 3395 are male students while 1634 are female students. Anthropometric Measurement Anthropometric measurement that were included in this study is body weight, height and Body Mass Index (BMI). 
The detail, procedure and equipment are explained specifically at the next sub-point.

\subsection{Body Weight}

Body weight was measured with digital body scale by following EUROFIT Battery test [16]. The scale was placed in a flat surface and before the test start, the reading of the scale will be checked and make sure the pointer is starting with 0 . Any accessories such as shoes, socks, necklace, bracelet, hand bag or sling bag if they have it, and any accessories they got in the pocket or body part will be removed to make sure the reading were taken accurately and purely without any extra unnecessary weight from the accessories. The participants must be standing upward at the middle of the scale and when reading of the weight was taken, the participant must look forward and stand still without doing any unnecessary movements. The reading will be recorded with the digit at the nearest 0.01 when reading measurement is stable enough. The precision of the weight scale was tested by comparing frequency of multiple readings of the digital scale result with using same participant before the actual test begun.

\subsection{Standing Height}

For standing height measurement, the device that will be used is portable stadiometer following the EUROFIT battery test procedure [16]. The reading scale taken which the reading is at the nearest $0.1 \mathrm{~cm}$. Participants standing on the flat surface of stadiometer while facing backward closely against the stadiometer's height scale. The participant standing still on stadiometer without shoe or socks with both of their feet closed together and their hands are put together closely at their waist. Participant must stand still without doing any awkward movement while reading was taken. While the participant standing still at the stadiometer, the facilitator will begin to take the reading of their height.

\subsection{Weight Status}

Weight status were measured as Body Mass Index [17]. The BMI, commonly known as the Quetelet Scale, is a metric to reflect the nutritional health. It is known as the weight of the person in kilograms divided by the square of the height of the person in meters.

After weight and height reading taken by the facilitator, the reading will be calculated based on the formula above and then the reading measurement will be classified into their class based on the WHO classification for BMI.
Table 1 Body Mass Index classification based on WHO

\begin{tabular}{cc}
\hline Status & BMI \\
Severe underweight & $0-15 / 9$ \\
Underweight & $16-18.5$ \\
Normal & $18.5-24.9$ \\
Overweight & $25.0-40.0$ \\
Obesity & Above 40 \\
\hline
\end{tabular}

\subsection{Fitness Test Procedure}

These are the details of the fitness test procedure and conducted and equipment used on fitness test.

\subsection{Standing Broad Jump}

Standing Broad Jump test (SBJ) was carried out by using standing broad jump mat. The participant standing behind the starting line marked on the mat with feet slightly open in the half squat position. Then, participant jump as far as they can with one amplifying swing. The reading measurement was taken at the back of the feet where the participant was landing. The participants were given twotime chance to try the jumping and the best distance the participant can get will be recorded. The test will be cancelled if the participant breaks the rule like not landing with both feet, jumping with one foot, both feet, legs and body moving forward or backward after their successfully landing on the mat.

\subsection{Sit and Reach}

Sit and reach test (SAR) was carried out by the sit and reach box by following procedure in EUROFIT battery test [18]. Participants were required to sit on the floor with their knees are fully extend with the bare feet positioned at the flat surface against the sit and reach box which was fixed against the wall. Participants were instructed to put place one hand on top of their hand with both palms are facing down and slowly stretch and reaching forward along the surface and trying to reach the end of the box as far as they can with maximum effort and hold the maximum flexion approximately in two second. The conductor will hold their knees with minimum pressure so that the participant knees did not raise up when the participant pushing the reading marker so there is no jerky movement happen in the test. To get the maximum reading, the reading was taken at decimal point in multiples of $0.5 \mathrm{~cm}$. Two chance trials were allowed and the longest distance were recorded. 


\subsection{Hand Wall Toss Test}

Hand wall toss test (HWT) was carried out by following the procedure in the Bruininks-Oseretsky Test of Motor Proficiency instrument, Second Edition (BOTMP-2) [19]. A target mark was placed at a one-meter distance from the wall. Adhesive tape was used to create a rectangular square shape target mark $(30 \mathrm{~cm} \times 30 \mathrm{~cm})$ and fixed to the wall as the target compartment. The distance between the target compartment and the floor is one metre. The participant stood behind the marked line and faced into the target mark during the test as in figure 8. Participants throw the ball against the target compartment on the wall with the dominant hand and caught it with non-dominant hand. There are ten attempts for the participant to try throwing the ball and capture it. The number of successful throw and captured will be recorded.

\subsection{Meter Sprint}

20 meter sprint (20MS) was carried out by following procedure in EUROFIT test battery [20]. Before starting the test, participants were instructed to stay at the standing position with intention ready to run like with placing one dominant leg at the starting point to act as a momentum starter for the participant to sprint. Tester will blow than whistle and the participant start the run. The time start to record when the participant starts to run from the starting line and finish recording time when the participant reached at the finishing line. Each participant is given 2 trials intermittently. Reading will be taken up to two decimal point (0.01) seconds.

\subsection{Conceptual study}

An ex-post facto study must be involved two variable that is dependent variable and independent variable. In this study, power, speed, coordination and flexibility were chosen as the dependent variable and gender is chosen as the independent variable while residential location is chosen as controlled variable or covariate. In other words, cognitive growth is depending on motor skills performance, gender and residential location. Figure 1 Shows summarization conceptual framework of this study.

\subsection{Pre-processing data}

The pre-processing data in this study included the data cleaning, test of normality, and Homogeneity Test. Data cleaning was required to detect and correcting missing, corrupt, irrelevant or inaccurate data records from this dataset then replace, repair or delete the data error. All the sample with missing values in the dataset was removed. Data has been filtered to determine the extreme upper outlier and lower outlier. To make this dataset more relevant, the extreme upper outlier was removed because it will likely will disturb the data analysis will possibly make a measurement error or typo during data key in process.

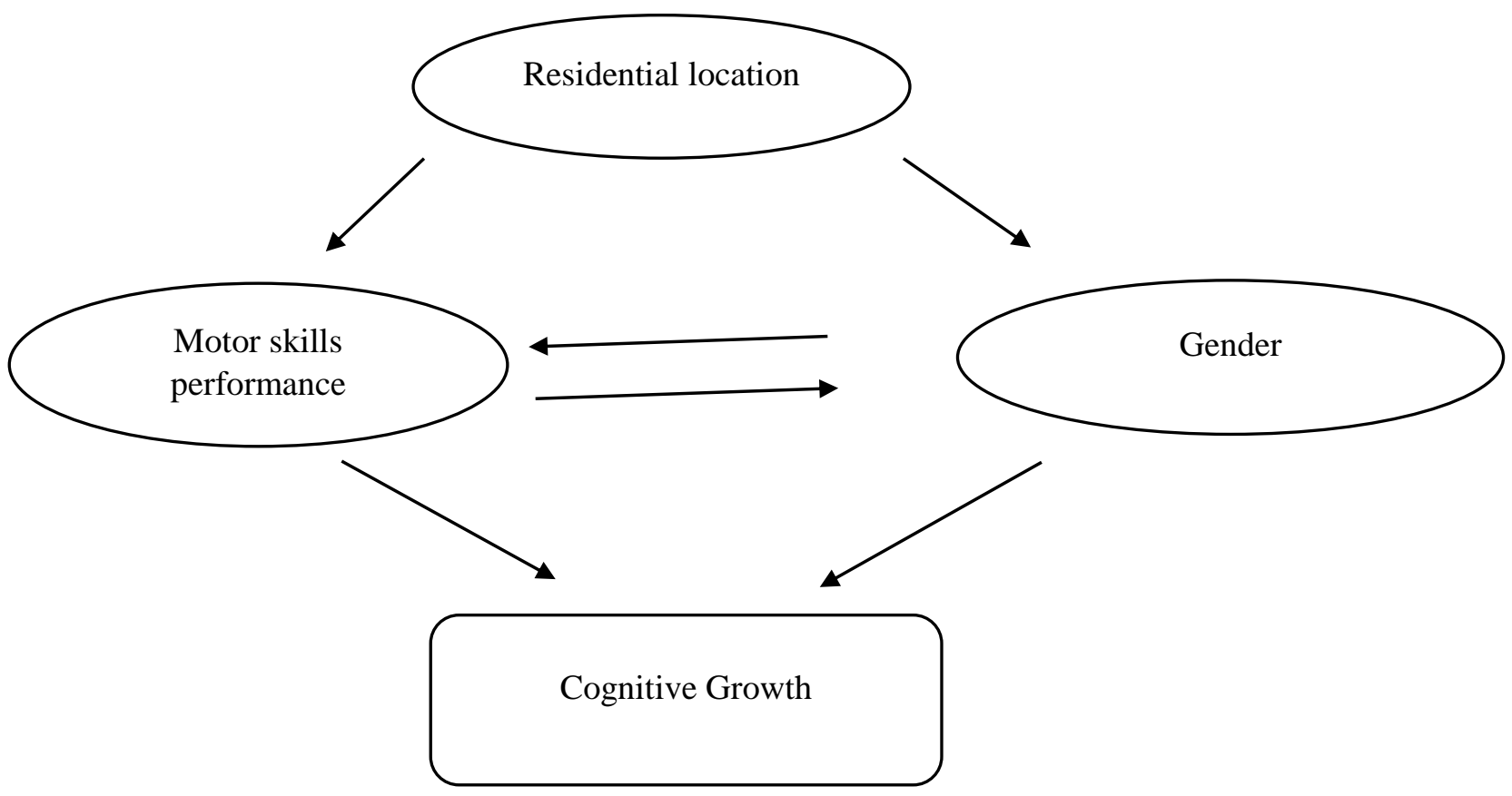

Figure 1 Conceptual framework of this study 


\subsection{Data analysis}

The statistical analysis in this study has been carried out as partition to chronology of objectives to be completed. First step is to pre-processing data that is including data cleaning and test of normality. Then, to complete the first objective, the first analysis that will be used is the unsupervised technique of Principal Component Analysis to see the major factor in this research. After that, in order to complete the last objective, Multiple Analysis Covariate of Variance was executed to find the differences and explore the potential of gross motor skills between male and female children of underweight children.

\section{RESULT ANALYSIS}

\subsection{Descriptive statistic}

The table above showed, the total of observation that involved in this study is 5027. The minimum value of power $(\mathrm{cm})$ is -3.2793 and the maximum value of power $(\mathrm{cm})$ is 2.3966 . Next, is the minimum value of flexibility $(\mathrm{cm})$ is -3.0804 and the maximum value of flexibility $(\mathrm{cm})$ is 2.2078. The minimum value for coordination (bil.) is 1.3612 , and the maximum value for coordination (bil.) is 1.7294. The minimum value for speed (sec) is -5.3156 and the maximum value for speed $(\mathrm{sec})$ is 1.3556. Then, frequency of minimum of power $(\mathrm{cm})$ is 2 and the frequency of maximum is 3 . The frequency of minimum for flexibility $(\mathrm{cm})$ is 12 and the maximum is 14 . The frequency of minimum for coordination (bil.) is 931 and the frequency of maximum is 334 . The frequency of minimum for speed (sec) is 1 and the maximum of frequency is 37 . Lastly, the median for power $(\mathrm{cm})$ is 0.0187 , the median for flexibility is 0.0250 , the median for coordination (bil.) is 0.0124 and the median for speed $(\mathrm{sec})$ is 0.2036 .

\subsection{Identifying key parameter}

For the first PCA analysis, based on the table 2, there are two major factors identified in this analysis, first one in the factor $1(\mathrm{~F} 1)$ is the gross motor skills for power is the one dominating factor after all of this factor with VFS value 0.7636 , the second major factor in the factor 2 (F2) is the gross motor skills for flexibility with VFS value 0.8899 .

For the second PCA analysis with varimax rotation, based on the table 3 there are two major factor identified in this analysis, first one in the factor $1(\mathrm{~F} 1)$ is the gross motor skills for power is the one dominating factor after all of this factor with VFS value 0.7162 , the second major factor in the factor 2 (F2) is the gross motor skills for flexibility with VFS value 0.9509 .

Table 2 Descriptive statistics for this research

\begin{tabular}{lcccc}
\hline \multicolumn{1}{c}{ Statistic } & Power $(\mathrm{cm})$ & Flexibility $(\mathrm{cm})$ & Coordination & Speed $(\mathrm{sec})$ \\
\hline Nbr. of observations & 5027 & 5027 & 5027 & 5027 \\
Minimum & -3.2793 & -3.0804 & -1.3612 & -5.3156 \\
Maximum & 2.3966 & 2.2078 & 1.7294 & 1.3556 \\
Freq. of minimum & 2 & 12 & 931 & 1 \\
Freq. of maximum & 3 & 14 & 334 & 37 \\
Range & 5.6758 & 5.2882 & 3.0906 & 6.6712 \\
Median) & -0.0187 & -0.0250 & 0.0124 & 0.2036 \\
Mean & 0.0000 & 0.0000 & 0.0000 & 0.0000 \\
Variance (n) & 1.0000 & 1.0000 & 1.0000 & 1.0000 \\
Standard deviation $(\mathrm{n})$ & 1.0000 & 1.0000 & 1.0000 & 1.0000 \\
\hline
\end{tabular}

Table 3 Factor loading of gross motor skills variable

\begin{tabular}{lllll}
\hline & F1 & F2 & F3 & F4 \\
\hline Power $(\mathrm{cm})$ & 0.7636 & 0.0320 & 0.1299 & -0.6316 \\
Flexibility $(\mathrm{cm})$ & 0.3385 & 0.8899 & -0.2478 & 0.1794 \\
Coordination & 0.6855 & -0.1356 & 0.5420 & 0.4668 \\
Speed $(\mathrm{sec})$ & -0.5574 & 0.4175 & 0.6941 & -0.1823 \\
\hline
\end{tabular}


Table 4 Factor loading of gross motor skills parameter after varimax rotation

\begin{tabular}{lll}
\hline & D1 & D2 \\
\hline Power $(\mathrm{cm})$ & 0.7162 & 0.2668 \\
Flexibility $(\mathrm{cm})$ & 0.0465 & 0.9509 \\
Coordination & 0.6938 & 0.0832 \\
Speed $(\mathrm{Sec})$ & 0.6593 & 0.2245 \\
\hline
\end{tabular}

Table 7 shows the result of multivariate analysis of comparison between the gross motor skills parameter and genders with the controlled effect of residential location. Based on the Post Hoc Comparison test, there is significant differences of all parameter for covariate residential location except for flexibility shows in table 6 Result of the MANCOVA analysis, the result shows reading of $p$ value is all significant for the parameter in this research. The $p$ value in this research means that there is significant differences between male and female 7 years old children. And this reading suggesting that both gender have their respectative dominant and lacks of gross motor skills that potentially to be expand or maintain and to boost the lacks of the gross motor skills performances. Box $M$ test in Table 4, showing that the covariances matrices on the parameters are equal across the groups. Tests the null hypothesis that the observed covariance matrices of the dependent variables are equal across groups. Therefore, the covariate of the residential is valid to be used in this study

Table 5 Result of Box's M test

\begin{tabular}{ll}
\hline Box's M & 40.771 \\
\hline F & 4.073 \\
df1 & 10 \\
df2 & 50637765.81 \\
Sig. & 0.000
\end{tabular}

Based on the Levene test in Table 5 all the parameters are equal variances are assumed except for the parameter for flexibility which is greater than .05 then the flexibility equal variances are not assumed. Tests the null hypothesis that the error variance of the dependent variable is equal across groups. Therefore, the multivariate analysis is valid to be used in this study.

Based on the pairwise comparison table 6 , for gross motor skills in term of power parameter, male children is greater than female with value for male (107.751) with standard deviation value (16.0953) while value for female is (97.156) with standard deviation value (15.1799).
Table 6 Result of Levene's Test

\begin{tabular}{lllll}
\hline & F & df1 & df2 & Sig. \\
\hline Power $(\mathrm{cm})$ & 13.664 & 1 & 5025 & 0.000 \\
Coordination & 9.994 & 1 & 5025 & 0.002 \\
Speed (sec) & 22.714 & 1 & 5025 & 0.000 \\
Flexibility (cm) & 1.112 & 1 & 5025 & 0.292
\end{tabular}

The mean differences for female are -10.622 . For gross motor skills in term of coordination parameter, male children are greater than female children with value for male (5.40) with standard deviation value (2.889) and for female value is (4.07) with standard deviation (2.752). The mean differences for female are -1.334 . For gross motor skills in term of speed parameter, male children are greater than female children with value for male (4.6622) with standard deviation value $(0.37946)$ while value for female is (4.7909) with standard deviation value is (0.34434). The mean differences for the female are 0.129. For the final gross motor skills in term of flexibility parameter, female children are greater than male children with value for female (26.299) with standard deviation value (4.2029) while male value is (26.013) with standard deviation value (4.2776)

\section{DISCUSSION}

Based on the finding founded in the first analysis of PCA, the major factors of the gross motor skills for underweight students are power and flexibility. This PCA result has shown contradict from the previous studies [21];[22]. In the earlier study, they stated that the power is the only gross motor skills is the major factor for underweight while in this study that power and flexibility are the major factor for underweight children.

The comparison of the mean value for the parameter between their study and this study is also different, for major factor for power, their mean value is 114.8(24.8) while in this study stating that the value of power for underweight children is 104.3(16.5), while for flexibility, their research stating the mean value is $27.4(5.8)$ while this research stating that value for flexibility for underweight children is 26.1(4.2). This is because the underweight children usually have a slender feet, that can be imply the underweight children foot have low body mass for their foot to support, so that support the findings that power is the major factor for underweight children[12]. 
Table 7 MANCOVA analysis result based on Pairwise Comparison

\begin{tabular}{lllll}
\hline Dependent Variable & (I) Gender & (J) Gender & Mean Difference (I-J) & Std. Error \\
\hline \multirow{2}{*}{ Power $(\mathrm{cm})$} & Male & Female & $10.622^{*}$ & \\
& Female & Male & $-10.622^{*}$ & 0.476 \\
\multirow{2}{*}{ Coordination } & Male & Female & $1.334^{*}$ & 0.476 \\
& Female & Male & $-1.334^{*}$ & 0.086 \\
Speed $(\mathrm{sec})$ & Male & Female & $-.129^{*}$ & 0.086 \\
& Female & Male & $.129^{*}$ & 0.011 \\
Flexibility $(\mathrm{cm})$ & Male & Female & $-.275^{*}$ & 0.011 \\
& Female & Male & $.275^{*}$ & 0.128 \\
& & & & 0.128 \\
\hline
\end{tabular}

As for flexibility, according to earlier findings[5], they stating that underweight has great flexibility because underweight children have a strong lower body muscle strength, but weak abdominal muscle strength, lack of muscle and fat in the abdominal, underweight may have great flexibility with this factor, but at the same time these results also indicate that underweight children are underweight.

There is also finding that significant between their study and this study that is children fitness performances is decreasing as the year and modernization increase. This pattern can be also be seen at earlier study [6], stating that from 1985 to 2014, there is decreasing trend of the children physical fitness performance for year to year due to the sedentary lifestyle as this can be related also with the earlier study [10], that found the children physical performances also decreasing due to the same factor; sedentary lifestyle.

There is sure will the underweight children motor performance will be decreasing due to the sedentary life style as shown in the earlier study[10], stating that underweight children are placed in the third over four group of BMI in parameter of time period of watching television and playing video games. Although in their research stating that underweight children time period is significantly better than overweight children, there is no doubt that even the underweight children can reach the time period level of watching television and playing video games like overweight due to the modernization as can be seen the trend of physical fitness performances frequently decreasing [3];[6].

According to the findings in the MANCOVA analysis, founded that male children are dominating with variable of gross motor skills power and coordination and female dominating. In term of physical fitness, male children perform better in power, speed and coordination while female perform better in flexibility. These research is contradict with the previous research that stating that for underweight children, male is dominating female in every all aspect [23], this research result is also similar with previous research stating that underweight male children dominate all gross motor skills except for female children dominating in flexibility [24]. This is similar according earlier study[11], stating that females were significantly less likely to start or sustain physical activity than were males. This is also similar to other research that stating the same thing [25]-[27]. Male are executing many physical activities and having advantages of having more testosterone that can create new blood cells, keeping bones and muscles strong and prompting growth spurts and this can be conclude that male have more muscle and stronger bones and growth and less oestrogen than female [28]. Female have less muscle mass and also female intend for having slimmer bodies especially in between the legs and this factors contribute to the female for why they great in flexibility[28].

\section{CONCLUSION}

Based on this research, can be concluded that both genders have their dominant factor of gross motor skills respective. Data analysis method used was believed as a good way for knowing the potential and weakness hold by the underweight children and this data analysis method also can be used for the social worker, minister and children development program manager to create an awareness in themselves for solving the underweight problem. In this research also tells that underweight children also excel in some abilities of gross motor skills although they are not good as the normal weight children that totally excel in gross motor skills performance. With all this research output, it can be simplified that the underweight children also have their potential in gross motor skills and this study believed the underweight children have a potential and talent to be expand to become more better than before if a earlier move can be executed.

\section{ACKNOWLEDGMENT}

University of Sultan Zainal Abidin (UniSZA) has partnered with the National Sports Institute (ISN) to obtain data on physical fitness among children. A grant for this study was given by the National Sports Institute (ISN). This research is entirely funded by the Institute. For the 
results of this study, the researchers would like to thank parents, guardians, school administrators, and participants for their good cooperation.

\section{REFERENCES}

[1] K. E. O'Dell, R. B. McCall, C. J. Groark, Supporting families throughout the international special needs adoption process. Children and Youth Services Review, 59 (2015) 161-170. DOI: https://doi.org/ 10.1016/j.childyouth.2015.11.008

[2] M. A. Adefuye, T. Dansu, Problems and Issues Relating to Physical Fitness in an Urban Setting. 5 (1) (2007).

[3] A. G. LeBlanc, J. P. Chaput, A. McFarlane, R. C. Colley, D. Thivel, S. J. Biddle, R. Maddison, S. T. Leatherdale, M. S. Tremblay, Active video games and health indicators in children and youth: a systematic review. PloS one, 8 (6) (2013) e65351. DOI: https://doi. org/10.1371/journal.pone.0065351

[4] A. Laukkanen, A. Pesola, M. Havu, A. Sääkslahti, T. Finni, Relationship between habitual physical activity and gross motor skills is multifaceted in 5-to 8year-old children. Scandinavian journal of medicine \& science in sports, 24 (2) (2014) e102-e110. DOI: https://doi.org/10.1111/sms.12116

[5] Y. Xu, M. Mei, H. Wang, Q. Yan, G. He, Association between weight status and physical fitness in Chinese Mainland children and adolescents: a crosssectional study. International journal of environmental research and public health, 17 (7) (2020) 2468. DOI: https://doi.org/10.3390/ijerph17072468

[6] D. Ao, F. Wu, C. F. Yun, X. Y. Zheng, Trends in physical fitness among 12-year-old children in urban and rural areas during the social transformation period in China. Journal of Adolescent Health, 64 (2) (2019) 250-257. DOI: https://doi.org/10.1016/j.jadohealth.20 18.08.021

[7] T. Mahmudiono, C. Segalita, R. R. Rosenkranz, Socio-ecological model of correlates of double burden of malnutrition in developing countries: A narrative review. International journal of environmental research and public health, 16 (19) (2019) 3730. DOI: https://doi.org/10.3390/ijerph16193730

[8] R. Micha, V. Mannar, A. Afshin, L. Allemandi, P. Baker, J. Battersby, L. Grummer-Strawn, 2020 Global nutrition report: action on equity to end malnutrition. 2020. https://eprints.mdx.ac.uk/id/eprint/30645

[9] J. Piaget, Intellectual evolution from adolescence to adulthood. Human development, 15 (1) (1972) 1-12. DOI: https://doi.org/10.1159/000271225
[10] S. Esmaeilzadeh, K. Ebadollahzadeh, Physical fitness, physical activity and sedentary activities of 7 to 11 year old boys with different body mass indexes. Asian journal of sports medicine, 3 (2) (2012) 105. DOI: 10.5812 asjsm.34709

[11] S. Armstrong, C. A. Wong, E. Perrin, S. Page, L. Sibley, A. Skinner, Association of physical activity with income, race/ethnicity, and sex among adolescents and young adults in the United States: findings from the National Health and Nutrition Examination Survey, 2007-2016. Jama Pediatrics, 172 (8) (2018) 732-740. DOI:10.1001/jamapediatrics.2018.1273

[12] M. Mauch, S. Grau, I. Krauss, C. Maiwald, T. Horstmann, Foot morphology of normal, underweight and overweight children. International journal of obesity, 32 (7) (2008) 1068-1075. DOI: https://doi. org/10.1038/ijo.2008.52

[13] S. J. Robertson, A. F. Burnett, J. Cochrane, Tests examining skill outcomes in sport: a systematic review of measurement properties and feasibility. Sports Medicine, 44 (4) (2014) 501-518. DOI: https://doi.org/ $10.1007 / \mathrm{s} 40279-013-0131-0$

[14] Y. Hachana, A. Attia, S. Nassib, R. J. Shephard, M. S. Chelly, Test-retest reliability, criterion-related validity, and minimal detectable change of score on an abbreviated Wingate test for field sport participants. The Journal of Strength \& Conditioning Research, 26 (5) (2012) 1324-1330. DOI: https:// doi.org/10.1519/JSC.0b013e3182305485

[15] A. B. H. M. Maliki, M. R. Abdullah, A. Nadzmi, M. A. R. Zainoddin, I. M. Puspitasari, N. F. A. Jibril, N. A. Nawi, S. M. Mat-Rasid, R. M. Musa, Z. Suhaili, N. A. Kamarudin S. K. S. Ali, Kids motor performances datasets. Data in brief, 34 (2021) 106582. DOI: https://doi.org/10.1016/j.dib.2020.106582

[16] C. Adam, V. Klissouras, M. Ravazzolo, R. Renson, W. Tuxworth, H. C. G. Kemper, W. Van Mechelen, H. Hlobil, G. Beunen H. Levarlet-Joye, EUROFITEuropean test of physical fitness. 1987.

[17] Z. Mei, L. M. Grummer-Strawn, A. Pietrobelli, A. Goulding, M. I. Goran, W. H. Dietz, Validity of body mass index compared with other body-composition screening indexes for the assessment of body fatness in children and adolescents. The American journal of clinical nutrition, 75 (6) (2002) 978-985. DOI: https://doi.org/10.1093/ajcn/75.6.978

[18] E. D. Ryan, K. L. Everett, D. B. Smith, C. Pollner, B. J. Thompson, E. J. Sobolewski, R.E. Fiddler, Acute effects of different volumes of dynamic stretching on vertical jump performance, flexibility and muscular endurance. Clinical physiology and functional imaging, 
34 (6) (2014) 485-492. DOI: https://doi.org/10.1111/ cpf. 12122

[19] J. C. Deitz, D. Kartin, K. Kopp, Review of the Bruininks-Oseretsky test of motor proficiency, (BOT2). Physical \& occupational therapy in pediatrics, 27 (4) (2007) 87-102. DOI: https://doi.org/10.1080/J006v27n0 4_06

[20] A. Zwierzchowska, A. Żebrowska, K. Gawlik, W. Smółka, B. Molik, M. A. Gomez, J. A. Navia, Coordination motor abilities and somatic growth of children and adolescents with hearing impairments. European Journal of Human Movement, 44 (2020) 95110. DOI: https://doi.org/10.21134/eurjhm.2020.44.504

[21] K. K. Mak, S. Y. Ho, W. S. Lo, G. N. Thomas, A. M. McManus, J. R. Day, T. H. Lam, Health-related physical fitness and weight status in Hong Kong adolescents. BMC public health, 10 (1) (2010) 1-5. DOIhttps://doi.org/10.1186/1471-2458-10-88

[22] S. Esmaeilzadeh, K. Ebadollahzadeh, Physical fitness, physical activity and sedentary activities of 7 to 11 year old boys with different body mass indexes. Asian journal of sports medicine, 3 (2) (2012) 105. DOI: 10.5812 asjsm.34709

[23] O. Abdelkarim, A. Ammar, K. Trabelsi, H. Cthourou, D. Jekauc, K. Irandoust, M. Taheri, K. Bös, A. Woll, N. L. Bragazzi, A. Hoekelmann, Prevalence of underweight and overweight and its association with physical fitness in egyptian schoolchildren. International journal of environmental research and public health, 17 (1) (2020) 75. DOI: https://doi.org/10.3390/ijerph17010075

[24] L. Kryst, A. Woronkowicz, A. JankowiczSzymańska, M. Pociecha, M. Kowal, J. Sobiecki, J. Brudecki, R. Żarów, Physical fitness of overweight and underweight preschool children from southern Poland. Anthropologischer Anzeiger; Bericht uber die biologisch-anthropologische Literatur, 73 (2) (2016). DOI: https://doi.org/10.1127/anthranz/2016/0561

[25] B. R. Belcher, D. Berrigan, K. W. Dodd, B. A. Emken, C. P. Chou, D. Spuijt-Metz, Physical activity in US youth: impact of race/ethnicity, age, gender, \& weight status. Medicine and science in sports and exercise, 42 (12) (2010) 2211. DOI: https://doi.org/10. 1249/MSS.0b013e3181e1fba9

[26] K. Li, D. Haynie, L. Lipsky, R. J. Iannotti, C. Pratt, B. Simons-Morton, Changes in moderate-to-vigorous physical activity among older adolescents. Pediatrics, 138 (4) (2016). DOI: https://doi.org/10. 1542/peds.2016-1372
[27] R. P. Troiano, D. Berrigan, K. W. Dodd, L. C. Masse, T. Tilert, M. McDowell, Physical activity in the United States measured by accelerometer. Medicine and science in sports and exercise, 40 (1) (2008) 181. DOI: https://doi.org/10.1249/mss.0b013e31815a51b3 .

[28] R. O. Deaner, D. Mitchell, More men run relatively fast in US road races, 1981-2006: a stable sex difference in non-elite runners. Evolutionary Psychology, 9 (4) (2011) 147470491100900410. DOI: https://doi.org/10.1177/147470491100900410 